\title{
Determinants of fish assemblage structure in Mount Itoupé mountain streams (French Guiana)
}

\author{
Sébastien Brosse ${ }^{1 *}$, Juan I. Montoya-Burgos ${ }^{2}$, Gaël Grenouillet ${ }^{1}$ and Nicolas Surugue ${ }^{3}$ \\ ${ }^{1}$ Laboratoire Évolution et Diversité Biologique, U.M.R 5174 UPS-CNRS-ENFA, Université Paul Sabatier, 118 route de Narbonne, \\ F-31062 Toulouse Cedex 4, France \\ 2 Department of Genetics and Evolution, University of Geneva, Sciences III, 30 quai Ernest Ansermet, 1211 Geneva, Switzerland \\ ${ }^{3}$ Parc Amazonien de Guyane, 1 rue Lederson, 97354 Remire-Montjoly, French Guiana
}

Received 20 December 2012; Accepted 6 March 2013

\begin{abstract}
Fish assemblages inhabiting the mountain streams of the Guiana shield have scarcely been studied. Here we investigated fish assemblages in eight headwater mountain streams of the Mount Itoupé (French Guiana), and tested how local freshwater fish assemblages are shaped by environmental characteristics. We show that Mount Itoupé streams host uneven species assemblages, characterized by low species richness (less than ten species per site) and a high proportion of small Siluriform species. Differences in fish assemblage composition between the sites were mainly due to basin identity, but regional climate and position of the site in the river gradient also had a significant effect, although of lower magnitude. In contrast, local habitat hardly affected fish richness, abundances or assemblage composition. Species richness increased along the upstream-downstream gradient, whereas fish abundance depended mainly on the slope orientation of Mount Itoupé. Although these results need confirmation on a larger amount of sampling sites, located on other Guianese mountains, this preliminary study shows that the mountain streams of the Guiana Shield, although rarely investigated, host not only uneven species assemblages, but also present an original combination of environmental determinants shaping fish assemblage structure. Those rare and original ecosystems hence deserve more attention and should be preserved from human disturbances.
\end{abstract}

Key words: Biomass / community structure / environmental filters / neotropical / richness

\section{Introduction}

Freshwater fish assemblages are shaped by various biotic and abiotic determinants that constitute a series of filters for the fauna that are nested across spatial and temporal scales (Tonn, 1990; Jackson et al., 2001). Within a biogeographic realm, the fish fauna is shaped by regional factors that determine the pool of species colonizing each basin. As most fish cannot cross dry land and/or salt water, each basin can be considered as a biogeographic island and hence only rarely share individual fish with its counterparts (Hugueny, 1989; Oberdorff et al., 2011). Inter-basin colonization is therefore a rare event due to tributary captures from one basin to another or variations in sea water levels (Hubert and Renno, 2006; Cardoso and Montoya-Burgos, 2009; de Mérona et al., 2012). The fish assemblage of each basin is hence dependent on equilibrium between immigration/emigration and speciation/extinction events (MacArthur and

\footnotetext{
*Corresponding author: sebastien.brosse@univ-tlse3.fr
}

Wilson, 1967; Oberdorff et al., 2011). The pool of species colonizing a basin is then screened based on the local climate, considering the potential differences in temperature or water availability that is, at least in part, responsible for assemblage characteristics of the tributaries (Tonn, 1990; Jackson et al., 2001). Within a tributary, the species assemblage is then distributed according to the upstream-downstream gradient (Huet, 1959; Vannote et al., 1980; Ibarra et al., 2005; Ferreira and Petrere, 2009). Finally, at the local habitat scale, both physical habitat features and biotic interactions determine the fish assemblage that co-occurs at a particular place on the stream (Tonn, 1990; Jackson et al., 2001). Although there is now a consensus to recognize this general hierarchical screening of the fish fauna (Jackson et al., 2001), examples that quantify the relative role of the local and regional factors in explaining assemblage composition remain scarce, particularly for tropical streams, which have received much less attention than temperate ones (Jackson and Sweeney, 1995; Ferreira and 


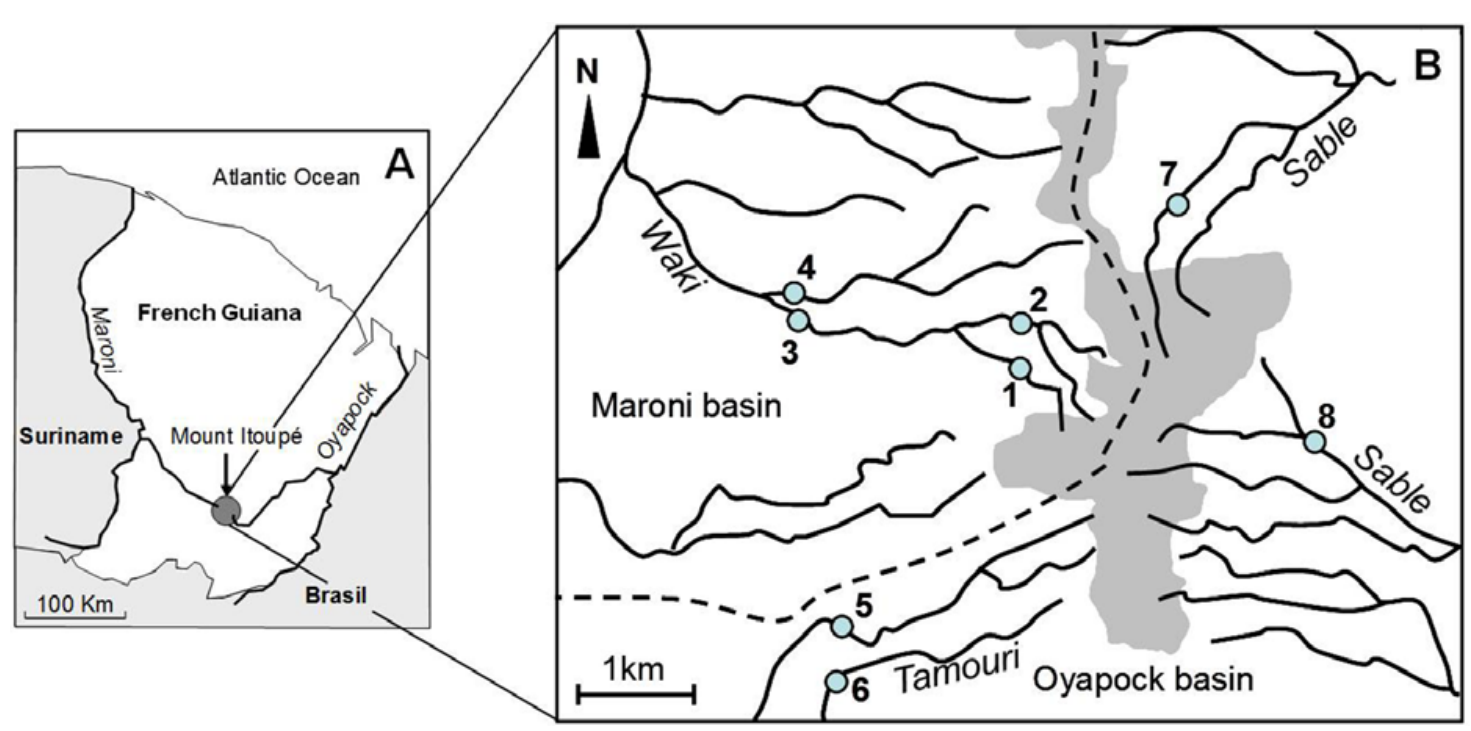

Fig. 1. Location of the study site. (A) General map of French Guiana showing the location of Mount Itoupé. (B) Detailed map of Mount Itoupé catchments with the eight study sites. The boundary between Maroni and Oyapock drainage basins is indicated by a dashed line. The grey area shows the mountain top (above $700 \mathrm{~m}$ a.s.1.).

Petrere, 2009). Within the Guiana Shield, the structure of freshwater fish assemblages inhabiting large rivers and lowland streams were fairly well studied, but in contrast headwater stream fishes remain scarcely investigated (see de Mérona et al., 2012 for a review). To our knowledge, the work of Mol et al. (2007) is the only published study on fish assemblages in such an ecosystem type. We focussed here on fish assemblages of Mount Itoupé (French Guiana) a part of the French Guiana National Park (Parc Amazonien de Guyane). This mountain hosts tributaries of the two main river basins of French Guiana and hence enabled us to investigate biogeographic effect. It also presents contrasting orientations, and hence climate conditions, as well as a strong altitudinal gradient that creates a marked upstream-downstream gradient as well as diverse local habitats. Our aim was first to conduct a first inventory of these remote and little known mountain stream fish assemblages. Then we quantified the relative roles of a series of environmental determinants accounting for regional to local steps (river basin, local climate, river gradient and local habitat) of the hierarchical faunal filters (Tonn, 1990; Jackson et al., 2001) on the fish assemblage of Mount Itoupé streams.

\section{Material and methods}

\section{Study site and sampling}

Mount Itoupé (Lat $3.01^{\circ} \mathrm{N}$, Long $53.06^{\circ} \mathrm{W}$ ) is located in central French Guiana and is the highest summit ( $820 \mathrm{~m}$ a.s.1.) of the Sommet Tabulaire mountain range. Mount Itoupé is one of the two highest mountains of French Guiana, the other being Mount Bellevue de l'Inini (851 $\mathrm{m}$ a.s.1.). Mount Itoupé has a general northsouth orientation. Western and eastern slopes are covered by dense rainforest, and only the tabular summit area is covered by cloudy mountainous forest. The western slope is drained by the Petite Waki and the Petit Tamouri rivers (hereafter called Waki and Tamouri) of the Maroni and Oyapock river basins, respectively. The eastern slope is drained by Sable river, which is a part of the Oyapock river basin (Fig. 1). Owing to the remoteness of the site, access to the base-camp (located between sites 1 and 2, see Fig. 1) was possible by helicopter only, all the equipment were manually carried from the base-camp to the sampling sites, a reason why we were unable to sample more sites or cover a longer distance to find distant sampling sites. The fish samples were collected during the dry season, in October 2010. It was not possible to plan a complementary field trip as the entire Mount Itoupé is a protected area.

We sampled eight sites (Fig. 1) belonging to the two main river basins (Maroni and Oyapock) to test for biogeographic effects, and sites located on both western and eastern slopes of the mountain to test for potential climate effects. We took samples from 636 to $285 \mathrm{~m}$ a.s.1., and altitude was recorded to account for upstreamdownstream gradient. For each site, two (three for site 7) contiguous stream sections were sampled totalling 17 sections. The length of each section (4.5-13.5 m) was set to encompass homogeneous habitat characteristics. For all the sections, the vegetation cover was dense primary forest and hence the streams were shaded with only a few illuminated patches. The overall physical characteristics of each section were summarized by measuring the stream width, water depth and current velocity along two to three transects depending on the sections. The roughness of the stream granulometry was visually estimated as the percentage of large-sized pebbles and boulders above $10 \mathrm{~cm}$ diameter. We also measured water conductivity, temperature, $\mathrm{pH}$, dissolved oxygen using a WTW meter and turbidity using a WTW turbidimeter. 


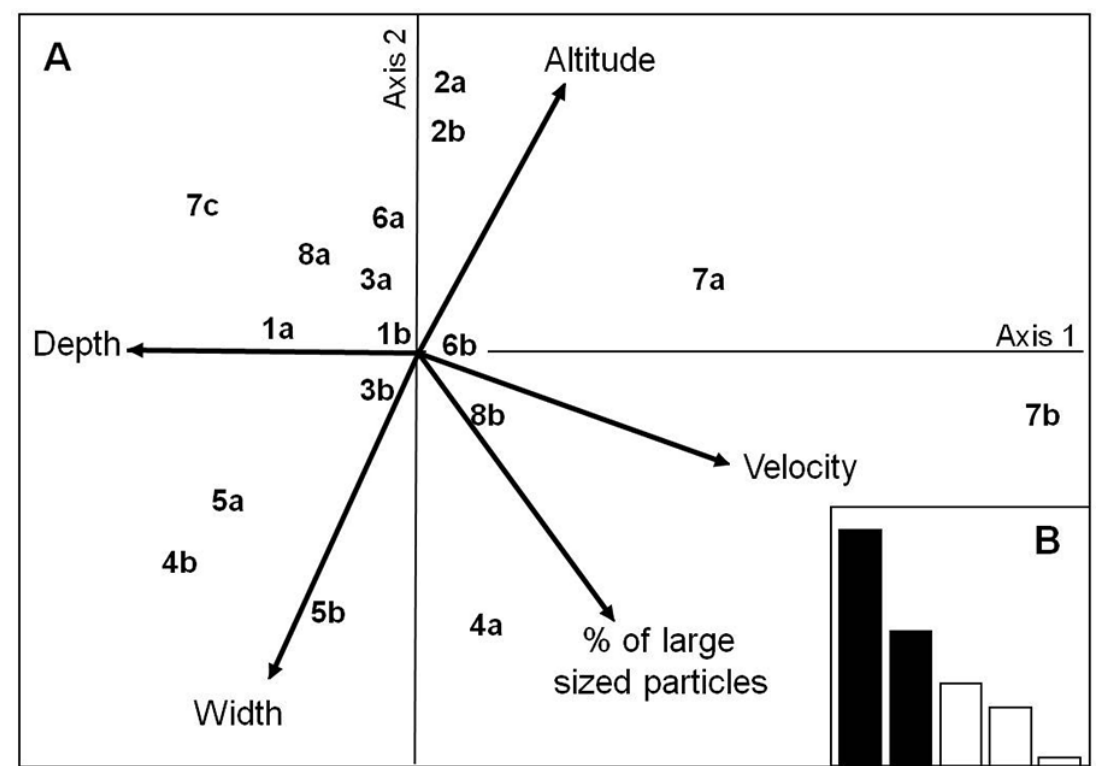

Fig. 2. PCA showing the distribution of the 17 stream sections according to environmental variables accounting for local habitat and upstream-downstream gradient. (A) Plane of the first two axes of the PCA. (B) Eigenvalues. Site codes as in Figure 1.

On each stream the two (three for site 7) contiguous sections were separated by fine-meshed stop nets (mesh size $4 \mathrm{~mm}$ ) to prevent fish from escaping the sampling area and fish displacement between sections. Fish sampling was done using rotenone. Two subsequent doses of PREDATOX mixed with water $(6.6 \%$ emulsifiable solution of rotenone extracted from Derris elliptica by Saphyr, Antibes, France) were introduced immediately upstream of the sampling area. Fish were then collected with fine meshed dip nets (2-mm mesh). This sampling method has been described in detail by Mérigoux et al. (1998), and has proved efficient to collect quantitative samples of fish assemblages in small neotropical streams (Mérigoux et al., 1998). This sampling protocol was validated by the National Park authorities that permitted us to sample fish with rotenone. Fish species were then identified according to Planquette $e t$ al. (1996), Keith et al. (2000) and Le Bail et al. (2000). Taxonomy was then updated according to Le Bail et al. (2012). Some specimens of each species were collected and were fixed in 5\% formaldehyde solution for taxonomic confirmation. For each species, all the fish were identified and counted.

\section{Data analyses}

As stream section descriptors (percentage of large particles, depth, width, physico-chemistry) can co-vary with the upstream-downstream gradient, we performed a principal component analysis to summarize environmental data. This also permitted us to distinguish between local and stream gradient effects, as the first axis mainly represented the local habitat, whereas the second axis mainly accounted for upstream-downstream gradient (see the Results section and Fig. 2). We hereafter used the coordinates of the 17 stream sections on axes 1 and 2 as surrogates of local habitat and stream gradient, respectively. We then performed generalized linear models (GLM, Gaussian family) to test the effects of biogeography (i.e., basin: Oyapock or Maroni), regional climate (i.e. slope of the mountain: West or East), upstreamdownstream gradient (principal component analysis (PCA) axis 2) and local habitat (PCA axis 1) on fish abundance and richness in the 17 stream sections. We finally ran a permutational MANOVA on the fish species abundance matrix to determine the relative roles of biogeography, climate gradient and local habitat determinants on the fish assemblages in the 17 stream sections. Permutational MANOVA is an analysis of variance using distance matrices performed by the function "adonis" of the "VEGAN" package (Oksanen et al., 2008) in the $R$ statistical software (R Core Team Development, 2008). This function partitions sums of squares using metric or semimetric distance matrices. The significance of the test was given by $F$-tests based on sequential sums of squares from 1000 permutations of the raw data. As the order of non-orthogonal variables can impact the outcome of significance testing in such procedures, the variables were introduced in the analysis according to the hierarchical filters proposed by Jackson et al. (2001). We hence first tested the effect of large temporal and spatial scale determinants and then gradually reduced the scale of the determinants tested in the analysis. This procedure allowed the measurement of the pure effect of each determinant after controlling for effects acting at higher scales.

\section{Results}

A large variation of physical characteristics (i.e. altitude, depth, width, current velocity and substratum 
Table 1. Range (minimum and maximum values), mean and standard deviation (SD) of physical and chemical characteristics of the 17 stream sections.

\begin{tabular}{|c|c|c|c|c|}
\hline & Min & Max & Mean & $\mathrm{SD}$ \\
\hline$\overline{\text { Altitude (m) }}$ & 285.00 & 636.00 & 473.65 & 138.65 \\
\hline Depth $(\mathrm{cm})$ & 1.00 & 22.00 & 13.70 & 4.85 \\
\hline Width $(\mathrm{cm})$ & 115.00 & 475.00 & 249.90 & 120.38 \\
\hline Velocity $\left(\mathrm{cm} . \mathrm{s}^{-1}\right)$ & 2.67 & 200.00 & 50.11 & 30.87 \\
\hline$\%$ large particles & 20.00 & 100.00 & 70.59 & 24.87 \\
\hline Conductivity ( $\mu \mathrm{s} . \mathrm{cm}^{-1}$ ) & 26.60 & 66.70 & 39.42 & 14.34 \\
\hline Oxygen $\left(\mathrm{mg} .1^{-1}\right)$ & 7.36 & 7.85 & 7.64 & 0.17 \\
\hline $\mathrm{Ph}$ & 6.80 & 7.25 & 7.00 & 0.15 \\
\hline Temperature $\left({ }^{\circ} \mathrm{C}\right)$ & 22.50 & 24.50 & 23.51 & 0.73 \\
\hline Turbidity (NTU) & 0.39 & 5.90 & 2.30 & 1.83 \\
\hline
\end{tabular}

Table 2. Fish species abundance (number of fish. $\mathrm{m}^{-2}$ ) in the eight study sites. The two (or three for site 7) stream sections in each site were pooled for clarity. The Waki and the Tamouri rivers flow on the western slope of the Mount Itoupé, whereas the Sable river flows on the eastern slope.

\begin{tabular}{|c|c|c|c|c|c|c|c|c|}
\hline \multirow{3}{*}{$\begin{array}{l}\text { Basin } \\
\text { Tributary } \\
\text { Site }\end{array}$} & \multirow{2}{*}{\multicolumn{4}{|c|}{$\begin{array}{c}\text { Maroni } \\
\text { Waki }\end{array}$}} & \multicolumn{4}{|c|}{ Oyapock } \\
\hline & & & & & \multicolumn{2}{|c|}{ Tamouri } & \multicolumn{2}{|c|}{ Sable } \\
\hline & 1 & 2 & 3 & 4 & 5 & 6 & 7 & 8 \\
\hline Ituglanis nebulosus & 0.80 & 0.65 & 0.94 & 0.69 & 0.16 & & 0.52 & 0.46 \\
\hline Lithoxus stocki & 0.09 & & 0.06 & 0.08 & & & & \\
\hline R. geayi & & 0.23 & 0.09 & & & & & \\
\hline Ancistrus cf. leucostictus & & & 0.15 & 0.02 & 0.11 & & & \\
\hline Guyanancistrus brevispinnis & & & & 0.01 & & & & \\
\hline C. zebra & & & & 0.03 & & & & \\
\hline R. igneus & & & & & 0.23 & 0.78 & 0.39 & 0.02 \\
\hline Lithoxus boujardi & & & & & 0.13 & & 0.32 & 0.10 \\
\hline Harttiella sp. & & & & & & & 1.45 & 1.22 \\
\hline
\end{tabular}

granulometry) was found among stream sections. On the contrary, thermal and chemical characteristics were similar among sections with the exception of conductivity which varied from 26 to $66 \mu$ S.cm ${ }^{-1}$ (Table 1). Preliminary analyses showed that contrary to physical descriptors, thermal and chemical variables (including conductivity) did not significantly affected fish richness, abundance or assemblage structure variations between sections (results not shown). In addition, the PCA summarizing environmental data was hardly affected by thermal and chemical variables. These weak informative variables were hence discarded from the final analyses.

The first two axes of the PCA performed on the environmental data (altitude, depth, width, water velocity and percentage of large particles) accounted for 44.7 and $26.0 \%$ of inertia, respectively. Axis 1 mainly represented the local habitat with a strong contribution of water depth and water velocity variables. Positive values hence indicate high velocity stretches with shallow water depth and a substantial proportion of large substrates, like waterfalls and riffles found in $7 \mathrm{a}$ and $7 \mathrm{~b}$ stream sections, respectively. In contrast, negative values account for deep areas and low water currents, as in the pools sampled in stream sections $7 \mathrm{c}, 5 \mathrm{a}$ or $4 \mathrm{~b}$. Axis 2 was more related to the upstream-downstream gradient with strong contributions of the altitude of stream section and of the channel width. It hence distinguishes upstream sites, like site 2, from downstream sites, like sites 4 and 5 (Fig. 2).

The 424 captured fish belonged to nine species, with a clear dominance of Siluriformes that accounted for six of the species (354 individuals). We also found two species of Rivulidae (Rivulus igneus and Rivulus geayi, 67 individuals) and one species of Characidae (three Characidium zebra). All the species were of small size (less than $10 \mathrm{~cm}$ total length) and the fish richness per site varied from one to five species with a fish abundance ranging from 0.63 to 2.68 fish.m ${ }^{-2}$ (Table 2). GLM showed that the differences in species richness can only be attributed to the upstream-downstream gradient, with a gradual richness increase along the gradient (Table 3a). Fish abundance on the other hand was not affected by a gradient effect, but by a slope orientation effect between western and eastern Mount Itoupé streams, which was the only variable found as having a significant effect on fish abundance (Table 3b).

More than $75 \%$ of the differences in fish taxonomic composition between sites were significantly explained by permutational MANOVA (Table 4). Basin scale effect was prominent as it explained for more than $40 \%$ of the variation in the data. The basin slope was also an important determinant as it accounted for more than $28 \%$ of the variation. The river gradient, although significant $(P<0.05)$, had a low effect $(6.4 \%)$ after accounting 
Table 3. Results of a GLM relating fish species richness (a) and fish abundance (b) to basin, slope, local habitat and river gradient descriptors of the 17 stream sections. ns, non-significant, ${ }^{*} P<0.05,{ }^{* *} P<0.01$.

\begin{tabular}{lrrr}
\hline & Estimate & $F$ & $P$ \\
\hline (a) Species richness & & & \\
Basin (Maroni-Oyapock) & -0.612 & 0.424 & 0.527 \\
Slope (east-west) & 1.518 & 2.064 & 0.176 \\
Local habitat (PCA axis 1) & -0.052 & 0.017 & 0.898 \\
River gradient (PCA axis 2) & -0.618 & 6.176 & 0.029 \\
(b) Abundance & & & $\mathrm{ns}$ \\
Basin (Maroni-Oyapock) & -0.192 & 3.724 & 0.078 \\
Slope (east-west) & 1.596 & 0.004 & $\mathrm{~ns}$ \\
Local habitat (PCA axis 1) & -0.027 & 0.800 & $\mathrm{~ns}$ \\
River gradient (PCA axis 2) & 0.125 & 0.067 & 0.419 \\
\hline
\end{tabular}

Table 4. Non-parametric permutational MANOVA assessing the effects of basin, slope, local habitat and river gradient on variations in taxonomic similarity between the 17 stream sections. MS is the mean-square value, and $F$ refers to $F$-test. The significance of the tests was checked using $F$-tests based on sequential sums of squares from 1000 permutations of the raw data (ns, non-significant, ${ }^{*} P<0.05, * * * P<0.001$ ).

\begin{tabular}{lcccc}
\hline & MS & $F$ & $R^{2}$ & $P$ \\
\hline Basin (Maroni-Oyapock) & 1.521 & 19.979 & 0.401 & $<0.001$ \\
Slope (East-West) & 1.072 & 14.082 & 0.282 & $<0.001$ \\
Local habitat (PCA axis 1) & 0.047 & 0.621 & 0.012 & 0.644 \\
River gradient (PCA axis 2) & 0.243 & 3.195 & 0.064 & 0.036 \\
Residuals & 0.213 & & 0.511 & $\mathrm{~ns}$ \\
\hline
\end{tabular}

for basin and slope effects. Finally, the local habitat was not identified by the permutational MANOVA as a variable significantly influencing the differences in fish composition $(P=0.644)$.

\section{Discussion}

Our current knowledge on the fauna inhabiting mountain streams of the Guyana Shield remains particularly meagre, and newly discovered taxa in such environments were recently reported, including seven highly endemic catfishes of the genus Harttiella (see Covain et al., 2012). Our study, which considers the entire fish assemblage, is only paralleled by a rapid biodiversity assessment program achieved on a Surinamese mountain by Mol et al. (2007). Moreover, these isolated mountain streams exhibit strong differences with South-eastern Brazilian Atlantic mountain streams and Andean streams both from physical and biological point of views (see, e.g., Ibanez et al., 2009; Pinto et al., 2009), making therefore comparisons difficult at the scale of the entire South American tropical region. A reason for the lack of data in Guyana Shield mountain streams is the high remoteness of these sites. Mount Itoupé is more than $50 \mathrm{~km}$ from the nearest human population, and access was only possible by helicopter as there are no roads or tracks in the forest. Our data, although limited, represent one of the first records of the fish assemblages in pristine mountain sites in the Guyana Shield (see Mol et al., 2007). This reference state data might therefore be of interest in the future to assess the impact of climate change or other human disturbances on these ecosystems.

Our results revealed that the fish assemblage of the Mount Itoupé streams was consistent with that found by Mol et al. (2007) in the Surinamese mountains, where fish assemblage was characterized by rivulids (Rivulus species) and small-sized silurids (Guyanancistrus, Harttiella and Ituglanis). Similarly, cichlids were absent from our sites and characids only represented by a single small rheophilic species $(C$. zebra). Our results also confirm that mountain streams of the Guiana Shield host a low fish richness that strongly contrasts with the higher richness found in streams of similar size located in lowland areas. Local richness was from one to five species in all the stream sections, whereas 2- to 20-fold more species (9-22 species) were found by Brosse et al. (2011) in headwater streams located below $100 \mathrm{~m}$ a.s.1. Similarly, Mol et al. (2007) recorded a sharp increase of fish richness in the foothills of the Nassau and Lely mountains (26 species) compared to the mountain streams (8-11 species). Richness, abundance and structure of the fish assemblage remained, however, quite variable within the mountain area of the Mount Itoupé.

Considering the relative roles of a series of potential determinants of assemblage structure revealed that the regional biogeographic effect (i.e. the basin) played a major role as it accounted for more than $40 \%$ of the variations in taxonomic similarity between sites. The biogeographic effect hence reflects the high beta-diversity 
that characterizes the Neotropical fish faunas (Hubert and Renno, 2006; Leprieur et al., 2011; Tedesco et al., 2012), and more precisely the high species turnover between the two basins, i.e., Oyapock contains 66 unique species and the Maroni basin 104, while only 138 species are shared between the two basins (Le Bail et al., 2012).

The orientation of the river basin also profoundly affected fish assemblage structure as it explained about $28 \%$ of the variability between assemblages. River orientation depends on the slope orientation of the mountain that can probably present contrasting rainfall patterns due to a Foehn effect, that is responsible for contrasting temperature and moisture regimes on the two sides of a mountain: the leeward side being warmer and dryer than the windward side, which also receives more abundant and more frequent rainfall (Baigorria et al., 2004). Despite the lack of local meteorological data for Mount Itoupé, it can be hypothesized that the climate differences between the two sides of the mountain affected the fish fauna through differences in stream productivity explaining significantly higher fish abundance on the eastern slope. In the same way, the presence of the genus Harttiella only on the eastern slope might be due to the strict necessity of high water current for this species that is very sensitive to drought reducing water velocity (Mol et al., 2007). This finding, sustains the hypothesis that the eastern slope could present greater climate stability than the western slope. It should nevertheless be noticed that our sampling effort is limited, and hence these results need to be confirmed by additional sampling.

The stream position along the upstream-downstream gradient had a lower (about 6\%), but still significant effect on fish assemblage, which was mainly due to a species richness increase going downstream. This results from an addition of species along the upstream-downstream gradient, more than a species replacement effect, as already shown in both temperate (e.g. Ibarra et al., 2005) and neotropical rivers (Araújo et al., 2009; de Mérona et al., 2012).

More surprisingly, the local habitat did not appear relevant for explaining the richness, abundance and assemblage structure. This is contrary to the current knowledge that considers that the local habitat is a major determinant of the assemblage composition (Gorman and Karr, 1978; Grossman et al., 1998). It also contrasts with habitat studies on small neotropical streams that underline the significant effect of the local habitat characteristics (Mérigoux and Ponton, 1999; Dibble and Pelicice, 2010; Brosse et al., 2011). It should, however, be noticed that the previous studies in the region only considered low altitude streams and the only study on mountain streams, at least partly, parallels our results, as the five mountain sites studied by Mol et al. (2007) exhibited similar species assemblages. It can therefore be hypothesized that the fauna inhabiting the mountain streams has experienced strong habitat filtering that sharply reduced the number of species able to colonize and establish in these areas also that selected species having similar habitat preferences. There might therefore be a low habitat segregation (at least at the reach scale) that explains the co-occurrence of the species independent of local habitat characteristics.

To conclude, it should be noted that despite the low richness of the sites considered, the streams of Mount Itoupe present an original species assemblage. These rare and original mountain ecosystems hence deserve more attention and need to be preserved from the multiple human disturbances that affect neotropical freshwater ecosystems (Hammond et al., 2007; Barletta et al., 2010; de Thoisy et al., 2010; Mol et al., 2012). In addition to the faunistic inventory, this work also permitted for the first time to investigate the hierarchical screening of the fish fauna (Jackson et al., 2001) in the Guiana Shield, and to show that biogeographical and regional scale determinants are more influent than the local habitat in the mountain streams. Our results should however be considered with caution, due to the limited amount of data and the short distance between sites. It would hence be interesting to expand this data to complementary and more distant sites and, in forthcoming studies, to integrate this upstream approach to a more comprehensive view of the determinants of fish assemblages across an entire upstreamdownstream gradient ranging from the source to the estuary.

Acknowledgements. We are grateful to the Parc Amazonien de Guyane for providing financial and logistic support for this work. SB and JMB are also grateful to the Parc Amazonien de Guyane for inviting us to participate in this field inventory of the Mount Itoupé streams. The authors are also grateful to Alain Thomas, who provided invaluable help during the field work. P. Winterton corrected the language and two anonymous referees provided helpful comments that improved the manuscript. SB and GG are part of the Labex CEBA (ANR-10-LABX-25).

\section{References}

Araújo F.G., Pinto B.C.T. and Teixeira T.P., 2009. Longitudinal patterns of fish assemblages in a large tropical river in southeastern Brazil: evaluating environmental influences and some concepts in river ecology. Hydrobiologia, 618, 89-107.

Baigorria G.A., Villegas E.B., Trebejo I., Carlos J.F. and Quiroz R., 2004. Atmospheric transmissivity: distribution and empirical estimation around the central Andes. Int. J. Climatol., 24, 1121-1136.

Barletta M., Jaureguizar A.J., Baigun C., Fontoura N.F., Agostinho A.A., Almeida-Val V.M.F., Val A.L., Torres R.A., Jimenes-Segura L.F., Giarrizzo T., Fabre N.N., Batista V.S., Lasso C., Taphorn D.C., Costa M.F., Chaves P.T., Vieira J.P. and Correa M.F.M., 2010. Fish and aquatic habitat conservation in South America: a continental overview with emphasis on neotropical systems. J. Fish Biol., 76, 2118-2176.

Brosse S., Grenouillet G., Gevrey M., Khazraie K. and Tudesque L., 2011. Small-scale gold mining erodes fish assemblage structure in neotropical streams. Biodivers. Conserv., 20, 1013-1026. 
Cardoso Y.P. and Montoya-Burgos J.I., 2009. Unexpected diversity in the catfish Pseudancistrus brevispinis reveals dispersal routes in a neotropical center of endemism: the Guyanas region. Mol. Ecol., 18, 947-964.

Covain R., Fisch-Muller S., Montoya-Burgos J.I., Mol J.H., Le Bail P.Y. and Dray S. 2012. The Harttiini (Siluriformes, Loricariidae) from the Guianas: a multi-table approach to assess their diversity, evolution, and distribution. Cybium, 36, 115-161.

de Mérona B., Tejerina-Garro F.L. and Vigouroux R., 2012. Fish-habitat relationships in French Guiana rivers: a review. Cybium, 36, 7-15.

de Thoisy B., Richard-Hansen C., Goguillon B., Joubert P., Obstancias J., Winterton P. and Brosse S., 2010. Rapid evaluation of threats to biodiversity: human footprint score and large vertebrate species responses in French Guiana. Biodivers. Conserv., 19, 1567-1584.

Dibble E.D. and Pelicice F.M., 2010. Influence of aquatic plant-specific habitat on an assemblage of small neotropical floodplain fishes. Ecol. Freshw. Fish, 19, 381-389.

Ferreira F.C. and Petrere M., 2009. The fish zonation of the Itanhaem river basin in the Atlantic forest of southeast Brazil. Hydrobiologia, 636, 11-34.

Gorman O.T. and Karr J.R., 1978. Habitat structure and stream fish ecology. Ecology, 59, 507-515.

Grossman G.D., Ratajczak R.E., Crawford M. and Freeman M.C., 1998. Assemblage organization in stream fishes: effects of environmental variation and interspecific interactions. Ecol. Monogr., 68, 395-420.

Hammond D.S., Gond V., de Thoisy B., Forget P.M. and DeDijn B., 2007. Causes and consequences of a tropical forest gold rush in the Guiana Shield, South America. Ambio, 36, 661-670.

Hubert N. and Renno J.F., 2006. Historical biogeography of South American freshwater fishes. J. Biogeogr., 33, 1414-1436.

Huet M., 1959. Profiles and biology of western European streams as related to fisheries management. Trans. Am. Fish. Soc., 88, 155-163.

Hugueny B., 1989. West-African rivers as biogeographic islands - species richness of fish communities. Oecologia, 79, 236-243.

Ibanez C., Belliard J., Hughes R.M., Irz P., Kamdem-Toham A., Lamouroux N. and Oberdorff T., 2009. Convergence of temperate and tropical stream fish assemblages. Ecography, 32, 658-670.

Ibarra A.A., Park Y.S., Brosse S., Reyjol Y., Lim P. and Lek S., 2005. Nested patterns of diversity revealed for fish assemblages in rivers of SW France. Ecol. Freshw. Fish, 14, 233-242.

Jackson D.A., Peres-Nieto P.R. and Olden J.D., 2001. What controls who is where in freshwater fish communities - the roles of biotic, abiotic, and spatial factors. Can. J. Fish. Aquat. Sci., 58, 157-170.

Jackson J.K. and Sweeney B.W., 1995. Present status and future directions of tropical stream research. J. N. Am. Benthol. Soc., 14, 5-11.

Keith P., Le Bail P.Y. and Planquette P., 2000. Atlas des poisons d'eau douce de Guyane (Tome 2- fascicule 1), MNHN, Paris, France, 286 p.
Le Bail P.Y., Keith P. and Planquette P., 2000. Atlas des poisons d'eau douce de Guyane (Tome 2- fascicule 2), MNHN, Paris, France, 307 p.

Le Bail P.Y., Covain R., Jegu M., Fish-Muller S., Vigouroux R. and Keith P., 2012. Updated checklist of the freshwater and estuarine fishes of French Guiana. Cybium, 36, 293-319.

Leprieur F., Tedesco P.A., Hugueny B., Beauchard O., Dürr H.H., Brosse S. and Oberdorff T., 2011. Partitioning global patterns of freshwater fish beta diversity reveals contrasting signatures of past climate changes. Ecol. Lett., 14, 325-334.

MacArthur R.H. and Wilson E.O., 1967. The Theory of Island Biogeography, Princeton University Press: Princeton, New Jersey, 203 p.

Mérigoux S. and Ponton D., 1999. Spatio-temporal distribution of young fish in tributaries of natural and flow-regulated sections of a neotropical river in French Guiana. Freshw. Biol., 42, 177-198.

Mérigoux S., Ponton D. and de Mérona B., 1998. Fish richness and species-habitat relationships in two coastal streams of French Guiana, South America. Environ. Biol. Fish., 51, 25-39.

Mol J.H., Wan Tong You K., Vrede I., Flynn A., Ouboter P. and van der Lugt F., 2007. Fishes of Lely and Nassau mountains, Suriname. In: Alonzo M.E. and Mol J.H. (eds), A rapid biological assessment of the Lely and Nassau plateaus, Suriname (with additional information on the Brownsberg Plateau). The RAP Bulletin of Biological Assessment. 43. Conservation International, $276 \mathrm{p}$.

Mol J.H., Vari R.P., Covain R., Willink P.W. and Fisch-Muller S., 2012. Annotated checklist of the freshwater fishes of Suriname. Cybium, 36, 263-292.

Oberdorff T., Tedesco P.A., Hugueny B., Leprieur F., Beauchard O., Brosse S. and Dürr H.H., 2011. Global and regional patterns in riverine fish species richness - a review. Int. J. Ecol. (Article ID 967631, 12 pages, doi:10.1155/2011/ 967631).

Oksanen J., Kindt R., Legendre P., O'Hara B., Simpson G.L., Stevens M.H.H. and Wagner H., 2008. VEGAN: community ecology package, v.1.13-8.

Pinto B.C.T., Araujo F.G., Rodriguez V.D. and Hugues R.M., 2009. Local and ecoregion effects on fish assemblage structure in tributaries of the Rio Paraba do Sul, Brazil. Freshw. Biol., 54, 2600-2615.

Planquette P., Keith P. and Le Bail P.Y., 1996. Atlas des poisons d'eau douce de Guyane (Tome 1), MNHN Paris, France, $429 \mathrm{p}$.

R Core Team Development, 2008. R: A Language and Environment for Statistical Computing, R foundation for Statistical Computing, Vienna, Austria.

Tedesco P.A., Leprieur F., Hugueny B., Brosse S., Durr H.H., Beauchard O., Busson F. and Oberdorff T., 2012. Patterns and processes of global riverine fish endemism. Global Ecol. Biogeogr., 21, 977-987.

Tonn W.M., 1990. Climate change and fish communities: a conceptual framework. Trans. Am. Fish. Soc., 119, 337-352.

Vannote R.L., Minshall G.W., Cummings K.W., Sedell J.R. and Cushing C.E., 1980. The river continuum concept. Can. J. Fish. Aquat. Sci., 37, 130-137. 